\title{
When foraging becomes unprofitable: energetics of diving in tidal currents by common eiders wintering in the Arctic
}

\author{
Joel P. Heath ${ }^{1,3, *}$, H. Grant Gilchrist ${ }^{2}$ \\ ${ }^{1}$ Centre for Wildlife Ecology and Behavioural Ecology Research Group, Simon Fraser University, 8888 University Drive, \\ Burnaby, British Columbia V5A 1S6, Canada \\ ${ }^{2}$ National Wildlife Research Centre, Canadian Wildlife Service, 1125 Colonel by Drive, Raven Rd, Carleton University, \\ Ottawa, Ontario K1A 0H3, Canada \\ ${ }^{3}$ Present address: Mathematical Biology, University of British Columbia, 121-1984 Math Rd., Vancouver, British Columbia \\ V6T 1Z2, Canada
}

\begin{abstract}
A variety of ecological, physiological and environmental factors influence the energy budgets of diving animals. For common eiders Somateria mollissima sedentaria wintering in sea ice habitats in the Canadian Arctic, time and energy costs of diving increase exponentially with tidal current speed. Here we use literature estimates of diving energetics and underwater dive data to quantitatively model net energy gain per dive cycle as a function of current speed. The model indicates a strong non-linear decrease in the profitability of diving with increasing currents, predicting that net energy gain per dive cycle will reach zero and become unprofitable at $1.21 \mathrm{~m} \mathrm{~s}^{-1}$ (at $11.3 \mathrm{~m}$ depth using baseline parameters from our study). As currents increase travel time, foraging time at the bottom decreases non-linearly, reaching a point where intake is inadequate to balance increasing diving and surface swimming costs. Sensitivity analysis indicates that this threshold is robust over a range of energy expenditure rates and is influenced most by energy intake rate, emphasising the importance of ecological factors such as prey abundance and quality. Eiders stop foraging and rest on the ice well below this threshold in weaker current regimes $\left(\sim 0.8 \mathrm{~m} \mathrm{~s}^{-1}\right)$, at about the point when profitability begins to decelerate. Behavioural time series of diving under constraints of strong tidal current regimes indicate that these eiders do occasionally dive in currents up to $\sim 1.2 \mathrm{~m} \mathrm{~s}^{-1}$, providing support for the energetic model. Eiders did not dive in faster currents, which could also be influenced by a physiological limit to swimming speed. We conclude that ocean currents can cause a non-linear decrease in net energy balance and are therefore an important and understudied consideration for diving animals. Many functional aspects of diving (e.g. locomotor costs or convective heat loss) have non-linear characteristics; these diminishing returns can be expected to play an important role in the dynamics of behavioural routines and the ability of organisms to respond to environmental variation.
\end{abstract}

KEY WORDS: Diving $\cdot$ Foraging $\cdot$ Energetics $\cdot$ Non-linear $\cdot$ Profitability $\cdot$ Winter ecology $\cdot$ Polynyas $\cdot$ Somateria mollissima sedentaria

\section{INTRODUCTION}

Understanding how the energetic costs of behavioural activities vary in relation to abiotic and biotic factors can provide important insights into the ecology of a species. Strategies which maximise net energy gains are expected to be favoured by natural selection (Schoener 1971). Among diving birds, a tradeoff often exists between energy gain from prey consumption and energy loss due to the high energetic costs associated with diving. In some situations, energy costs of foraging may actually exceed that gained from prey 
consumption (e.g. Frederick \& Klaas 1982, Paulus 1984). The energetics of diving have been studied extensively and indicate that diving entails a significant increase in energy cost over resting metabolism: e.g. tufted duck Aythya fuligula (Woakes \& Butler 1983, Bevan et al. 1992), lesser scaup Aythya affinis (Stephenson 1994), common and thick billed murre Uria spp. (Croll \& McLaren 1993). High energy expenditure is required to counter buoyancy and hydrodynamic drag during diving (Lovvorn et al. 1991, Stephenson 1994) and often to offset the increased thermoregulatory costs of compressed insulation (Wilson et al. 1992) and thermal conductivity in cold water (Jenssen et al. 1989). This combination of biomechanical and thermoregulatory costs makes diving a highly demanding mode of foraging.

Previous research on common eiders Somateria mollissima sedentaria wintering in polynyas in the Canadian Arctic indicated that the time and energy costs of diving increase non-linearly with tidal current speed (i.e. increased travel time and number of wing strokes required for descent: Heath et al. 2006, 2007). Additionally, the exponentially increasing travel time associated with diving in strong currents entailed a nonlinear decrease in the time eiders spent foraging at depth (Heath et al. 2007). We are interested here in quantitatively modeling the energetics of these relationships and evaluating the possibility that a critical current speed exists beyond which diving is no longer a profitable activity. Observations indicate that eiders stop foraging and leave the water to sit on the edge of the sea ice during fast tidal currents. We combine underwater observations of eider diving behaviour with literature estimates of the energetic costs of diving activities in order to evaluate how net energy gain per dive cycle changes across the natural range of tidal currents faced by eiders in the wild $\left(0\right.$ to $\left.1.5 \mathrm{~m} \mathrm{~s}^{-1}\right)$. The robustness of the predicted relationship and relative importance of various components of the model are evaluated using sensitivity analysis. Using radio telemetry data, we compare the results of energetic modeling with diving activity of eiders foraging in very fast current regimes in the wild. We discuss the implications of current speed and diminishing net energy balance in understanding the foraging ecology of diving animals.

\section{MATERIALS AND METHODS}

A variety of physiological and biomechanical research has been done on the energetics of diving in common eiders. In particular, research by Lovvorn et al. (1991), Guillemette et al. (1992), Nehls (1995), Hamilton et al. (1999), Hawkins at al. (2000), Brinkman et al. (2003) and Richman \& Lovvorn (2008) provided substantial information allowing empirically based estimates of energy expenditure rates for the various components of the dive cycle to be made. We used the information from these published sources to establish baseline estimates of energetic rates, which we describe for each activity. All parameters were subject to sensitivity analysis within $\pm 10 \%$, which was further expanded to $\pm 50 \%$ to demonstrate that our general results were substantially robust. We start with a basal metabolic rate (BMR) of $4 \mathrm{~W} \mathrm{~kg}^{-1}$ (Brinkman et al. 2003), which is included in each activity. We first estimate energetic costs of thermoregulation and then determine the energy costs for each component of the dive cycle: descent, foraging on the bottom, ascent, and surface swimming. We summarise our energy estimates in Table 1; calculations are presented in $\mathrm{W} \mathrm{kg}^{-1}$ to facilitate comparisons with other species. The Hudson Bay common eider is substantially larger than other species and sub-species, weighing between 2.5 and $3.0 \mathrm{~kg}$ (and even up to $3.17 \mathrm{~kg}$ : S. Jamieson pers. comm.), and so we conducted our energetic analysis based on a $2.75 \mathrm{~kg}$ bird.

Study site. The behavioural component of this research is based on underwater video observations conducted at polynyas (openings in the sea ice, e.g. maintained by strong tidal currents) around the Belcher Islands in Hudson Bay, Nunavut, Canada. In particular, we consider a small $11.3 \mathrm{~m}$ deep polynya at Ulutsatuq, where a population of $\sim 100$ eiders spent the winter foraging over extensive sub-tidal mussel beds. See Heath (2007) and Heath et al. $(2006,2007)$ for further details and regression equations relating the duration of each component of the dive cycle to tidal current speed.

Heat loss to air and water. On the surface, a swimming bird is partly in the water and partly exposed to air; both must be considered in determining energetic costs due to heat loss. Based on biophysical assump-

Table 1. Somateria mollissima sedentaria. Summary of baseline estimates of energetic costs of various diving related activities for a $2.75 \mathrm{~kg}$ bird diving at $11.3 \mathrm{~m}$ (estimated from literature sources and using empirical regression equations: Heath et al. 2006, 2007). The rate of energy expenditure for locomotion during surface swimming was determined to be a Gompertz function $F$ of current speed. For all details see 'Materials and methods'

\begin{tabular}{|lc|}
\hline Component & Cost (Watts) \\
\hline Surface pause & $27.50-F$ (current) \\
On ice & 16.50 \\
Descent & 44.00 \\
At depth & 30.25 \\
Ascent & 27.50 \\
Intake & 174.00 \\
\hline
\end{tabular}


tions of the thickness and conductance of fat and the feather air layer, Brinkman et al. (2003) estimate heat loss for eiders at $5^{\circ} \mathrm{C}$ to be $200 \mathrm{~W} \mathrm{~m}^{-2}$ in water and $60 \mathrm{~W} \mathrm{~m}^{-2}$ in air. The surface area of the $2 \mathrm{~kg}$ eider considered in their model is $\sim 0.13 \mathrm{~m}^{2}$ (Brinkman et al. 2003); so, assuming that approximately half of the bird is submerged while swimming on the surface, $0.065 \mathrm{~m}^{2}$ would be subject to cooling by air and $0.065 \mathrm{~m}^{2}$ to water. This yields a heat loss of $6.5 \mathrm{~W} \mathrm{~kg}^{-1}$ to water and $1.95 \mathrm{~W} \mathrm{~kg}^{-1}$ to air; at $5^{\circ} \mathrm{C}$, when added to a BMR of $4 \mathrm{~W}$ $\mathrm{kg}^{-1}$, this gives an estimated cost for the whole bird of $7.9 \mathrm{~W} \mathrm{~kg}^{-1}$ in air, and $12.5 \mathrm{~W} \mathrm{~kg}^{-1}$ whilst resting on the water surface. Respirometry of common eiders in air (smaller sub-species weighing $\sim 1.66$ to $1.79 \mathrm{~kg}$ ) has yielded values of $3.68 \mathrm{~W} \mathrm{~kg}^{-1}$ at $5^{\circ} \mathrm{C}$ (Jenssen et al. 1989), $5.30 \mathrm{~W} \mathrm{~kg}^{-1}$ at $5^{\circ} \mathrm{C}$ (Gabrielsen et al. 1991), and $4.29 \mathrm{~W} \mathrm{~kg}^{-1}$ at an unspecified temperature (probably 14 to $19^{\circ} \mathrm{C}$ : Hawkins et al. 2000), suggesting that the biophysical model (Brinkman et al. 2003) overestimates costs in air at $5^{\circ} \mathrm{C}$ by 49 to $155 \%$.

For resting on the water surface, respirometry yielded $5.03 \mathrm{~W} \mathrm{~kg}^{-1}$ (Jenssen et al. 1989) for common eiders $(1.66 \mathrm{~kg})$ at $5^{\circ} \mathrm{C}$, and $5.91 \mathrm{~W} \mathrm{~kg}^{-1}$ for whitewinged Scoters $(1.09 \mathrm{~kg})$ at $9^{\circ} \mathrm{C}$ (Richman \& Lovvorn 2008), suggesting that the biophysical model overestimates costs of floating on water at $5^{\circ} \mathrm{C}$ by 136 to $249 \%$. However, a higher value of $10.25 \mathrm{~W} \mathrm{~kg}^{-1}$ was reported for common eiders at 14 to $19^{\circ} \mathrm{C}$ (Hawkins et al. 2000), indicating that the metabolic rate of floating eiders can be higher in some circumstances. For floating eiders in respirometry experiments, air temperature was probably very similar to water temperature (Kaseloo \& Lovvorn 2006) and there was no appreciable air movement to enhance heat loss by convection. In contrast, floating eiders at our field site may experience above water air temperatures which are much lower than water temperatures, and high winds may cause substantial convective heat loss (Chappell et al. 1989). Equations provided by Jenssen et al. (1989) for air temperatures of $-35^{\circ} \mathrm{C}$ suggested a cost of $5.91 \mathrm{~W} \mathrm{~kg}^{-1}$ in air only; if a wind chill based on $25 \mathrm{~km} \mathrm{~h}^{-1}$ winds is incorporated, a cost of $6.96 \mathrm{~W} \mathrm{~kg}^{-1}$ in air only is suggested. We conservatively use a value of $6.0 \mathrm{~W} \mathrm{~kg}^{-1}$ for costs of resting in air only (i.e. costs for resting on the ice edge). Lacking definitive measurements for floating on water, we used a value of $10 \mathrm{~W} \mathrm{~kg}^{-1}$ for floating eiders at 14 to $19^{\circ} \mathrm{C}$ based on measurements by Hawkins et al. (2000), which is $82.5 \%$ higher than the value of $5.48 \mathrm{~W} \mathrm{~kg}^{-1}$ for eiders floating on water at $0^{\circ} \mathrm{C}$ measured by Jenssen et al. (1989); this is likely to be conservative for conditions at our field site. Additional studies on thermoregulatory costs, particularly in colder air and water temperatures, are clearly required.

Surface swimming. An important component of the surface energy budget involves swimming, particu- larly in maintaining position as tidal currents increase. Stephenson et al. (1989) report that drag increases strongly at swimming speeds over $0.5 \mathrm{~m} \mathrm{~s}^{-1}$. Hawkins et al. (2000) measured the oxygen consumption of common eiders swimming on the water at various speeds in a flume tank. They found that oxygen consumption increased exponentially above $1 \mathrm{~m} \mathrm{~s}^{-1}$ and that no ducks were able to swim at speeds greater than $1.3 \mathrm{~m} \mathrm{~s}^{-1}$ in their experiments. At $1.3 \mathrm{~m} \mathrm{~s}^{-1}$, the volume of oxygen consumed was 1.8 times that whilst resting on the surface of the water. They report no change in oxygen consumption up to $1.0 \mathrm{~m} \mathrm{~s}^{-1}$, however at 1.0 , 1.1 and $1.2 \mathrm{~m} \mathrm{~s}^{-1}$, their data indicate an increase in oxygen consumption of 1.18, 1.36 and 1.6 times (respectively) that whilst resting on the water. As eiders could not swim against currents faster than $1.3 \mathrm{~m} \mathrm{~s}^{-1}$, we assume for the purposes of the present model that they would be carried by currents faster than this and would therefore maintain an oxygen consumption rate 1.8 times higher than at rest. This allows us to fully explore the influence of other energetic parameters instead of truncating the model at $1.3 \mathrm{~m} \mathrm{~s}^{-1}$. For currents $<1.0 \mathrm{~m} \mathrm{~s}^{-1}$, Brinkman et al. (2003) similarly suggest only a slight increase of $0.3 \mathrm{~W} \mathrm{~kg}^{-1}$ for speeds starting at $0.3 \mathrm{~m} \mathrm{~s}^{-1}$, which we applied for current speeds from 0.3 to $0.99 \mathrm{~m} \mathrm{~s}^{-1}$. Hawkins et al. (2000) did not provide a regression equation for oxygen consumption as a function of swimming speed. As it was desirable to keep our energetic equations continuous across their range, we performed a curve fitting exercise using the values of the multiplication factors listed above. The most accurate curve describing the relationship between the energetic multiplication factor for basal metabolic rate (MULTIPLE) and swim speed (SPEED) was a Gompertz curve, a sigmoidal function, which explained $99.6 \%$ of the variation. This equation was:

MULTIPLE $=1.016+0.7977 \cdot \mathrm{e}^{-\mathrm{e}^{[10.24(0.9631 \text { SPEED })+1]}}$

Given that eiders often maintain their position on the surface, we assumed that surface swimming speed was equal to current speed and used Eq. (1) to determine the energetic costs of swimming as a multiple of surface resting cost (BMR + surface heat loss) with respect to current speed.

Descent. Our previous research indicated that the total number of wing strokes and the duration of descent increased non-linearly with current speed. Stroke rate and swim speed (relative to the moving water) were maintained within a narrow range across current speeds (Heath et al. 2006). Therefore, while the total time and energy costs of descent change with current speed, the rate of energy expenditure during descent should be fairly constant. Heath et al. (2006) 
noted that eiders always dove directly into oncoming currents, ending upstream of their surface departure point at an estimated dive angle of 0 to $20^{\circ}$. It is possible that increased drag in faster currents could lead to a decrease in dive angle (i.e. more vertical descent), although there is no data currently available to test this possibility. A slight change in dive angle induced by oncoming currents could compensate for increases in drag without entailing additional energetic costs. In either case, additional costs of drag not compensated for by small changes in dive angle are likely to be substantially smaller than the large increase in costs due to increased travel time and wing strokes on a given dive in fast currents (see Heath et al. 2006).

Changes in current speed could influence the rate of convective heat loss while underwater; however, given eiders swim at a relatively constant rate with respect to the water during descent (Heath et al. 2006), heat loss would not be expected to change substantially due to convective changes associated with current speed. Additionally, heat generated from exercise during diving likely compensates for heat losses (Kaseloo \& Lovvorn 2006). Based on equations from a simulation model for spectacled eiders that accounts for changes in buoyancy with depth (Lovvorn et al. 2009), the total mechanical cost of a $9.46 \mathrm{~s}$ descent to $11.3 \mathrm{~m}$ is $\sim 57.09 \mathrm{~J} \mathrm{~kg}^{-1}\left(6.03 \mathrm{~W} \mathrm{~kg}^{-1}\right)$. New estimates of oxygen consumption for a wing-propelled sea duck descending to $2 \mathrm{~m}$ depth (Richman \& Lovvorn 2008) suggest that the aerobic efficiency for that model should be $\sim 0.37$ (J.R. Lovvorn, pers. comm.). For a dive to $11.3 \mathrm{~m}$, those equations yield an estimated mechanical cost of $6.03 \mathrm{~W} \mathrm{~kg}^{-1}$, for an aerobic cost of $6.03 / 0.37=16.3 \mathrm{~W}$ $\mathrm{kg}^{-1}$. This value is about 4 times the BMR we are using, and is therefore quite reasonable when compared with other published values for diving ducks (review in De Leeuw 1996). We used a value of $16 \mathrm{~W} \mathrm{~kg}^{-1}$ for common eiders diving to $11.3 \mathrm{~m}$ at our study site.

Foraging on the bottom. While foraging on the bottom, eiders use only their feet to counter buoyancy and move from patch to patch (Heath 2007). Work against buoyancy at the bottom varies substantially with depth, and the equations in Lovvorn et al. (2009) for estimating the cost of bottom foraging in spectacled eiders do not apply to depths shallower than $30 \mathrm{~m}$ (J. R. Lovvorn, pers. comm.). During bottom foraging, almost all mechanical work is done against buoyancy, which at $11.3 \mathrm{~m}$ depth is only $45 \%$ of the buoyancy at $2 \mathrm{~m}$ (Lovvorn et al. 1991, Wilson et al. 1992). Consequently, the respirometry value of $13.37 \mathrm{~W} \mathrm{~kg}^{-1}$ for whitewinged scoters foraging at the bottom at $2 \mathrm{~m}$ depth (Richman \& Lovvorn 2008) will be only $\sim 45 \%$ of the value at $11.3 \mathrm{~m}$ depth, or $6.0 \mathrm{Wkg}^{-1}$. However, the value for scoters was measured at only $9^{\circ} \mathrm{C}$ and not $-1.8^{\circ} \mathrm{C}$ as in our study area. The volume of the insula- tive air layer in the plumage will also be substantially more compressed at 11.3 than at $2 \mathrm{~m}$. A model by Grémillet et al. (1998) estimated that heat loss to the water increases by about $85 \%$ when the volume of the plumage air layer decreases to $45 \%$ of that at the water surface; work rates at the bottom are also much lower than during descent and produce less heat from exercising muscles to replace lost heat. We therefore increased the estimated cost of bottom foraging at $11.3 \mathrm{~m}$ for common eiders at our field site by $85 \%$, from 6 to $11 \mathrm{~W} \mathrm{~kg}^{-1}$.

Ascent. Eiders foraging at $11.3 \mathrm{~m}$ depth in our study area are still positively buoyant and we observed that they passively ascended to the surface when they simply stopped kicking their feet. We therefore consider locomotor costs of ascent to be negligible at this foraging depth and assumed the costs of ascent were the same as those for resting on the surface of the water (i.e. $10 \mathrm{~W} \mathrm{~kg}^{-1}$ : see above).

Behavioural parameters. We used the regression equations from Heath et al. $(2006,2007)$ to determine descent duration, bottom duration and ascent duration as a function of current speed. When diving for mussels, eiders dove for an average duration of $58.47 \mathrm{~s}$ $( \pm 5.32 \mathrm{SD})$, across current velocities from 0.0 to $1.0 \mathrm{~m}$ $\mathrm{s}^{-1}$ (see Heath et al. 2007). We calculated a minimum required surface pause duration for each dive to be $58 \mathrm{~s}$ using the empirical regression equation for eiders wintering in the Gulf of St. Lawrence (Ydenberg \& Guillemette 1991). Although surface pause durations in our study were sometimes substantially longer, we were only interested in the energy budget over a minimum required surface pause, which this value closely approximated (Heath et al. 2007).

To calculate the energy costs for each component of a dive cycle (descent, foraging, ascent, and surface pause), we multiplied our above estimates of energy expenditure rates (summarised in Table 1) by the duration of each component predicted by the regression equations (from Heath et al. 2006, 2007) across current velocities from 0.0 to $1.8 \mathrm{~m} \mathrm{~s}^{-1}$. Fig. 1 indicates the predicted relationship between energy expenditure and current speed for each component of the dive cycle, using the baseline estimates summarised in Table 1.

Intake rates. An analysis of the mass of food in the gullets (esophagus) of 13 common eiders (collected by local hunters at the Belcher Islands while the birds were feeding on the water) contained (average $\pm \mathrm{SD}$ ) $15 \pm 10 \mathrm{~g}(95 \% \mathrm{CI}=5.4 \mathrm{~g}$ : S. Jamieson, unpubl. data). Our primary intent here is only to consider mussels; however, some of these birds were collected at locations other than our primary study area at Ulutsatuq polynya (i.e. other polynyas and floe edges around the Belcher Islands) and therefore contained other prey items. Common eiders collected in Greenland that had 

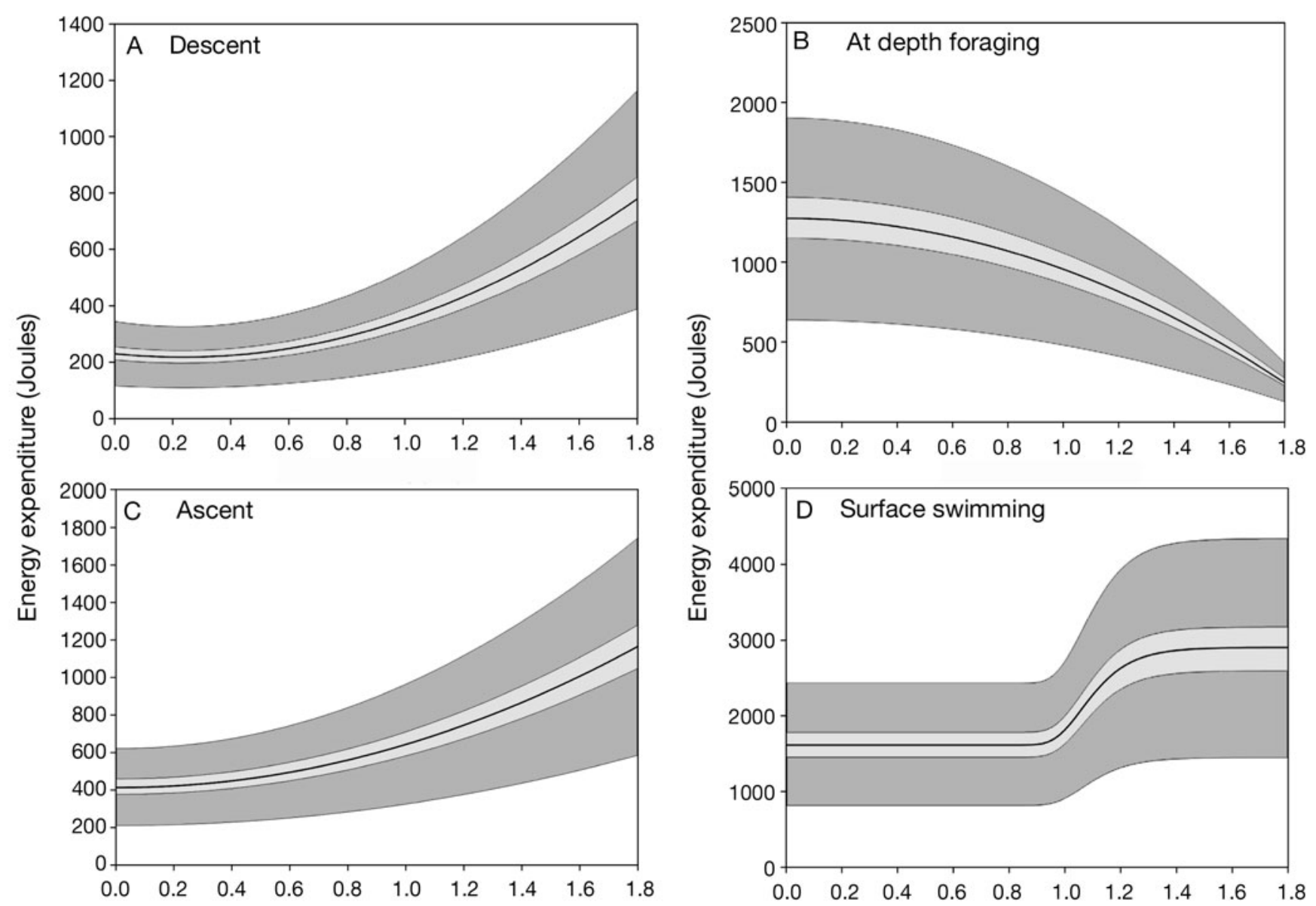

Current speed $\left(\mathrm{m} \mathrm{s}^{-1}\right)$

Fig. 1. Somateria mollissima sedentaria. Estimated energy expenditure per dive cycle (rate of expenditure times duration of activity) for: (A) descending to depth, (B) foraging at depth, (C) ascending and (D) swimming on the surface, all as a function of current speed. Solid black line: baseline energetic estimates, light grey areas: $10 \%$ change in baseline parameters under sensitivity analysis, dark grey areas: $50 \%$ change in baseline parameters under sensitivity analysis. Note the difference in scale on the vertical axes

exclusively mussels in the gullet contained $11.2 \pm 9.8 \mathrm{~g}$ (95\% CI $=3.8$ g: S. Jamieson, unpubl. data), which suggests these values of gullet contents are reasonable. While the gullet can act as a storage organ (Guillemette 1994), unlike studies in other regions, eiders wintering at the Belcher Islands did not dive in regular foraging bouts before resting (see Heath 2007) and frequently paused for long periods on the surface before diving again (183 $\mathrm{s} \pm 158 \mathrm{SD})$. This duration should be adequate to move most mussels from the gullet into the gizzard for processing; we therefore expect that many of the mussels present in the gullet of eiders at our study site could have been obtained within a single dive. We use $10 \mathrm{~g}$ as a baseline estimate of the mass of prey consumed per dive and consider a range of 5 to $15 \mathrm{~g}$ in our sensitivity analysis; the wide range should more than account for the possibility of food in the gizzard being acquired from multiple dives. Of course, a wide variety of factors affect the abundance, quality and availability of prey in the field; natural variation is likely to be substantially greater than any minor changes we might make to this estimate. We demonstrate below that this intake rate is well within that observed for other eider species, suggesting it is quite reasonable.

To convert total intake of wet mussel mass into energy intake rate first requires assumptions about the size class of mussels taken on average. Eiders often select mussels within a narrow size range (Bustnes \& Erikstad 1990, Bustnes 1998). A size distribution of mussels in the gullet contents were only available for a single individual that was diving at our specific field site (Ulutsatuq polynya); data for 26 individuals were available for common eiders wintering in Greenland 
(S. Jamieson, unpubl. data). A typical mussel length of $20 \mathrm{~mm}$ was selected for further analysis, as it was halfway between the distribution of Greenland birds and the bird from our study site. Based on the empirical regression equations of Guillemette et al. (1992), a mussel $20 \mathrm{~mm}$ in length would have a total mass of $1.1 \mathrm{~g}$ and contain $0.058 \mathrm{~g}$ dry mass of flesh. Brinkman et al. (2003) report an energy content of $22.5 \mathrm{~kJ} \mathrm{~g}^{-1}$ dry mass, meaning each $20 \mathrm{~mm}$ mussel would contain $\sim 1.305 \mathrm{~kJ}$ of usable energy.

Eiders swallow mussels whole, requiring significant energetic costs for digestive processing. These costs include crushing the shells in the muscular gizzard, absorptive digestion and heating the prey. Nehls (1995) estimated the digestion costs to be $14 \%$ of usable energy, which would mean $0.1827 \mathrm{~kJ}$ per $20 \mathrm{~mm}$ mussel. Brinkman et al. (2003) provide formulae to calculate the costs of heating prey as a function of length, which indicates a cost of $0.1522 \mathrm{~kJ}$ per $20 \mathrm{~mm}$ mussel. However, recent research by Kaseloo \& Lovvorn (2006) indicates that heat substitution from exercise and the heat increment of feeding/grinding mussels is likely more than adequate to compensate for heating the prey, particularly for birds diving deep in cold water and feeding on high protein prey such as mussels (all characteristics at our field site). We therefore do not include the $0.1522 \mathrm{~kJ}$ cost of heating the mussels as estimated by Brinkman et al. (2003). Based on the work of Nehls (1995), Brinkman et al. (2003) report a $\mathrm{N}$ to $\mathrm{kJ}$ conversion factor of 0.007 for converting crushing forces (from Piersma et al. 1993) into crushing costs, which indicates a cost of $0.357 \mathrm{~kJ}$ per $20 \mathrm{~mm}$ mussel. Total digestive processing costs are therefore estimated to be $0.5397 \mathrm{~kJ}$ per mussel, which yields a net gain per mussel of $0.7653 \mathrm{~kJ}$.

Given a $20 \mathrm{~mm}$ mussel weighs $\sim 1.1 \mathrm{~g}$ (fresh mass), $10.0 \mathrm{~g}$ of mussels in the gizzard suggests that $\sim 9.1$ mussels of $20 \mathrm{~mm}$ length would be consumed per dive for a net intake of $6.96 \mathrm{~kJ}$. Given that mussels are a sessile prey, we adopted the assumption of Houston \& Carbone (1992) that, on average, there is a constant prey energy intake rate per time spent foraging at depth. We therefore used the average bottom time of $40 \mathrm{~s}$ (Heath et al. 2007) to estimate a net energy intake rate of $174 \mathrm{~W}$ during time spent on the bottom. This corresponds to a mussel intake of 0.228 mussels per second, well within the intake rate functional response curves reported for spectacled eiders Somateria fischeri (Richman \& Lovvorn 2003) when feeding on similar sized clams; this could even be considered conservative, given that mussels in eider habitats occur at substantially higher densities (e.g. 1720 to 7330 ind. $\mathrm{m}^{-2}$ : Hamilton 2000). Of course, the energy content of mussels can vary among individuals and among seasons (see Hamilton et al. 1999), and widespread natural variation in mussel size abundance, quality, and prey captured per dive is likely to be far more important than minor adjustments in these parameter estimates.

Dive cycle energetics. Using the baseline estimates summarised in Table 1, net energy gain per dive cycle was estimated by (1) summing the costs of descent, foraging, ascent and surface pausing, and (2) subtracting this from the net energy gain from foraging. This provided a curve of net energy per dive cycle as a function of current speed. From this curve we could calculate the intercepts (i.e. the net energy gain per dive cycle at slack currents $\left[0.0 \mathrm{~m} \mathrm{~s}^{-1}\right]$ ) and the critical current speed at which net energy gain per dive cycle switched from positive to negative. Sensitivity analysis was conducted by altering each parameter (see above) and determining the new intercepts (critical current speed and slack current energy intake) and how much they differed proportionally from baseline estimates.

Behavioural time series using radio telemetry. To test the appropriateness of the threshold predicted by the model, we evaluated the fastest current speeds at which eiders were observed diving during 2 very strong tidal current regimes associated with a new moon. Eiders often stop foraging at much slower current speeds in weaker tidal regimes; however, our purpose here was to evaluate the upper limits of current speeds predicted by the model. In accordance with the guidelines of the Sanikiluaq Hunters and Trappers Association, we temporarily attached radio telemeters (RI-2B Transmitters for common eider: 9.0 g, 164.027$164.575 \mathrm{~Hz}$, Holohil Systems) to the surface plumage on the backs of individuals using superglue. Data collection computers (DCC) were connected to radio receivers (DCC II with R4000 Scientific Receiver, Advanced Telemetry Systems) and used to measure the number of pulses transmitted by each radio within a $2 \mathrm{~s}$ interval every $12 \mathrm{~s}$. As birds remained in range of the receiver for the duration of the study, $\sim 2$ to 3 transmitted pulses were received and recorded by DCC in each interval. The only exception occurred when the birds were underwater during dives; in these cases, no pulses were received and we could determine that the eiders were underwater. Dives last $\sim 1$ min (Heath et al. 2007) and so this difference in the number of transmitted pulses could be used to determine the occurrence and time of day of every dive made by each individual throughout the study. Using these behavioural time series, we evaluated the current speed at which eiders stopped and started foraging (prior to and following the peak tidal currents, respectively). Data were available for 6 March 2003 (17 individuals) and 7 March 2003 (7 individuals) during strong peaks in tidal currents associated with a new moon, 2 wk before the equinox. Data were averaged across individuals for comparison with the upper limits to current speed pre- 
dicted by the energetic model. Tidal current speed was measured every $5 \mathrm{~min}$ for the duration of the study using Nortek Aquadopp current loggers (see Heath et al. 2006 for details).

\section{RESULTS}

The change in energy expenditure for each component of the dive cycle (surface pausing, descent, foraging at the bottom and ascent) is presented in Fig. 1 as a function of current speed for the baseline values presented in Table 1, as well as the sensitivity analyses for a 10 and $50 \%$ change from baseline values (light and dark regions, respectively). The energetic costs of surface pausing increased sigmoidally as a function of current speed (due to the assumption that eiders swam at the same speed as currents in order to maintain position up to a maximum sustainable speed of $1.3 \mathrm{~m} \mathrm{~s}^{-1}$ ). As current speed increased, the total energy costs of travel time (descent and ascent) increased, due to an increase in the duration of travel with current speed (Heath et al. 2006, 2007). In contrast, the energy costs of foraging on the bottom decreased with current speed as eiders spend less time foraging at depth in fast currents (Heath et al. 2007). Corresponding with the decrease in foraging time per dive cycle, gross energy gain per dive cycle also declined as a function of current speed (Fig. 2).

A strong non-linear decrease in net energy gain per dive cycle was observed with increasing current speed (Fig. 3), particularly once currents reach $\sim 0.8 \mathrm{~m} \mathrm{~s}^{-1}$.

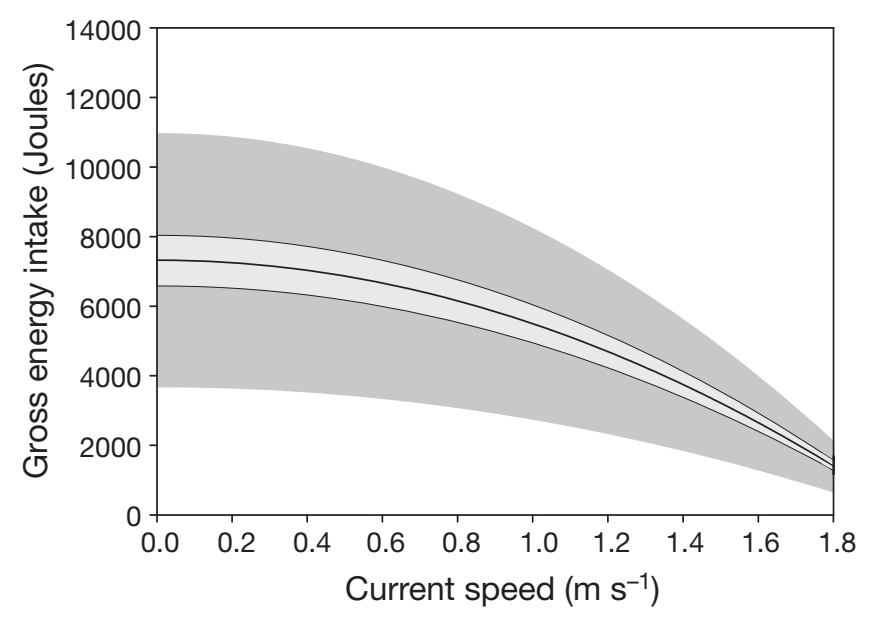

Fig. 2. Somateria mollissima sedentaria. Estimated rate of gross energy intake per dive cycle (descent, bottom foraging, ascent and subsequent pause). Gross intake rates are discounted by energy required to process and digest mussels, but not for energy expenditure (see Fig. 1). Solid black line: baseline energetic estimate $(174 \mathrm{~W})$, light grey areas: $10 \%$ change in intake rate, dark grey area: $50 \%$ change in intake rate

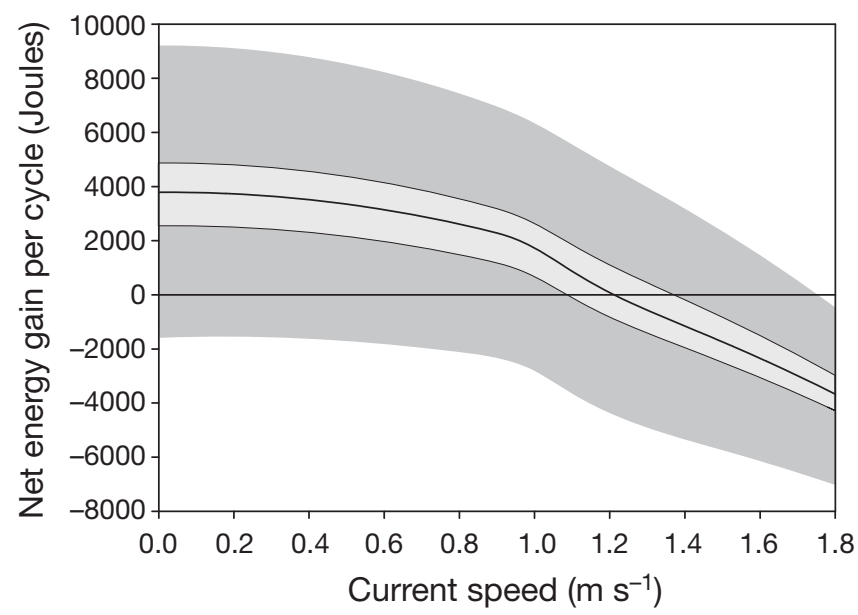

Fig. 3. Somateria mollissima sedentaria. Output of the energetic model for a depth of $11.3 \mathrm{~m}$, indicating net energy gain per dive cycle as a function of current speed. Intersection of the net energy function with the zero net energy axis indicates the critical current speed at which net energy per dive cycle switches from positive to negative. Solid black line: model output with all parameters at baseline and a critical current speed intercept of $1.21 \mathrm{~m} \mathrm{~s}^{-1}$. Light grey area: sensitivity analysis when all energy expenditure estimates are simultaneously increased or decreased by $10 \%$, while intake rate is simultaneously decreased or increased by $10 \%$, respectively (critical current speed 1.10 to $1.40 \mathrm{~m} \mathrm{~s}^{-1}$ ). Dark grey area: sensitivity analysis for a simultaneous $50 \%$ change in all rates, which demonstrates the robust decelerating shape of this relationship across substantial parameter variation. The exact intercepts are determined primarily by prey intake rate, which is expected to vary considerably across different field conditions

Despite extensive parameter variation in sensitivity analysis, the strong decelerating relationship was robust, indicating that diving will become unprofitable at current speeds within the range observed at this study site. At baseline values (Table 1), this curve changes from positive to negative energy gain per dive cycle at a critical current speed of $1.21 \mathrm{~m} \mathrm{~s}^{-1}$. The results also indicated a net energy gain per dive cycle of $4282.87 \mathrm{~J}$ would be achieved in slack currents.

Sensitivity analysis for each parameter (Tables 2 \& 3 ) indicates that the energetic model is robust to wide variation in our energetic estimates. Further, even with a $50 \%$ change in all the estimated energy expenditure rates, the predicted critical current speed and net energy gain at slack currents changed relatively little. However, while the decelerating shape of the curve was robust across all sensitivity analyses, the specific values of these intercepts were sensitive to the rate of energy intake. The predicted critical current speed changed rather substantially with a $\pm 50 \%$ change in prey intake rate, but still fell within the natural variation in tidal amplitude observed in this study system (up to $\sim 1.5 \mathrm{~m} \mathrm{~s}^{-1}$ ). As expected, net energy 
Table 2. Somateria mollissima sedentaria. Sensitivity analysis $( \pm 10 \%, \pm 50 \%)$ of percent change (\% Diff.) in energy estimates of surface costs, descent, foraging on the bottom, ascent and intake rate on the predicted critical current speed at which net energy gain over the dive cycle switches from positive to negative

\begin{tabular}{|c|c|c|c|c|c|c|c|c|}
\hline \multirow[t]{2}{*}{ Parameter } & \multicolumn{2}{|c|}{$-+10 \%$} & \multicolumn{2}{|c|}{$--10 \%-$} & \multicolumn{2}{|c|}{$-+50 \%-$} & \multicolumn{2}{|c|}{$-50 \%$} \\
\hline & $\begin{array}{c}\text { Current } \\
\text { speed } \\
\left(\mathrm{m} \mathrm{s}^{-1}\right)\end{array}$ & $\begin{array}{c}\% \\
\text { Diff. }\end{array}$ & $\begin{array}{c}\text { Current } \\
\text { speed } \\
\left(\mathrm{m} \mathrm{s}^{-1}\right)\end{array}$ & $\begin{array}{c}\% \\
\text { Diff. }\end{array}$ & $\begin{array}{c}\text { Current } \\
\text { speed } \\
\left(\mathrm{m} \mathrm{s}^{-1}\right)\end{array}$ & $\begin{array}{c}\% \\
\text { Diff. }\end{array}$ & $\begin{array}{c}\text { Current } \\
\text { speed } \\
\left(\mathrm{m} \mathrm{s}^{-1}\right)\end{array}$ & $\begin{array}{c}\% \\
\text { Diff. }\end{array}$ \\
\hline Surface & 1.18 & 2.81 & 1.25 & 3.55 & 1.08 & 11.1 & 1.45 & 19.7 \\
\hline Descent & 1.20 & 0.83 & 1.22 & 0.83 & 1.16 & 4.13 & 1.27 & 4.96 \\
\hline Bottom & 1.20 & 0.83 & 1.22 & 0.83 & 1.15 & 4.96 & 1.27 & 4.96 \\
\hline Ascent & 1.17 & 3.30 & 1.25 & 3.30 & 1.04 & 14.0 & 1.44 & 19.0 \\
\hline Intake & 1.28 & 5.79 & 1.15 & 4.96 & 1.48 & 22.3 & 0.40 & 66.9 \\
\hline
\end{tabular}

Table 3. Somateria mollissima sedentaria. Sensitivity analysis $( \pm 10 \%, \pm 50 \%)$ of percent change (\% Diff.) in energy estimates surface costs, descent, foraging on the bottom, ascent and intake rate on the predicted net energy gain per dive cycle at slack current. The predicted energy gain and percent difference from baseline (3786 J) are shown for each case

\begin{tabular}{|c|c|c|c|c|c|c|c|c|}
\hline \multirow{2}{*}{ Paramater } & \multicolumn{2}{|c|}{$-10 \%$} & \multicolumn{2}{|c|}{$-10 \%-$} & \multicolumn{2}{|c|}{$-+50 \%$} & \multicolumn{2}{|c|}{$-50 \%$} \\
\hline & $\begin{array}{c}\text { Gain } \\
(\%)\end{array}$ & $\begin{array}{c}\% \\
\text { Diff. }\end{array}$ & $\begin{array}{c}\text { Gain } \\
(\%)\end{array}$ & $\begin{array}{c}\% \\
\text { Diff. }\end{array}$ & $\begin{array}{c}\text { Gain } \\
(\%)\end{array}$ & $\begin{array}{c}\% \\
\text { Diff. }\end{array}$ & $\begin{array}{c}\text { Gain } \\
(\%)\end{array}$ & $\begin{array}{c}\% \\
\text { Diff. }\end{array}$ \\
\hline Surface & 3624 & 4.28 & 3948 & 4.28 & 2976 & 21.4 & 4597 & 21.4 \\
\hline Descent & 3745 & 1.08 & 3828 & 1.11 & 3579 & 5.47 & 3993 & 5.47 \\
\hline Bottom & 3659 & 3.35 & 3914 & 3.38 & 3150 & 16.8 & 4423 & 16.8 \\
\hline Ascent & 3480 & 8.08 & 4093 & 8.11 & 2255 & 40.4 & 5318 & 40.5 \\
\hline Intake & 4519 & 19.4 & 3054 & 19.33 & 7448 & 96.7 & 124 & 96.7 \\
\hline
\end{tabular}

\section{DISCUSSION}

Our empirically based energetic model indicates that the energetic costs of diving and surface swimming increase non-linearly as the speed of tidal currents increase, whilst time spent foraging at the bottom decreases non-linearly. As a result, net energy gain over a dive cycle decreases to a point where foraging can become unprofitable. Foraging gains from benthic mussels under decreasing foraging durations at the bottom are eventually inadequate to balance short term energy budgets. For the average intake rates estimated for mussels at our field site, the predicted critical current speed at which net energy gain switches from positive to negative $\left(1.21 \mathrm{~m} \mathrm{~s}^{-1}\right.$ at $11.3 \mathrm{~m}$ deep$)$ is within the range of observed tidal current velocities in winter habitats of eider ducks (polynyas are kept open by tidal currents which can exceed $1.5 \mathrm{~m} \mathrm{~s}^{-1}$ ). Eiders often stop foraging and rest on the ice edge at current speeds of $\sim 0.8 \mathrm{~m} \mathrm{~s}^{-1}$ (Heath et al. 2007),

gain in slack currents changed substantially with these large changes in prey intake. Compared to other parameters, intake rate had the greatest influence on model results in sensitivity analysis. The rate of energy intake during time spent foraging on the bottom therefore appears to be the most important parameter influencing energy budgets of eiders over the dive cycle.

\section{Comparison of model output to observed diving behaviour}

Fig. 4 shows the average current speeds at which eiders stopped and started diving for 2 strong diurnal tidal current profiles (associated with a new moon in March 2003). The majority of eiders did not dive in currents greater than $\sim 1.0 \mathrm{~m} \mathrm{~s}^{-1}$, although several individuals dove close to the predicted energetic threshold of $1.21 \mathrm{~m} \mathrm{~s}^{-1}$. For both tidal current regimes (Fig. 4), the critical current speed predicted by the model fell just under $+1 \mathrm{SD}$ of the current speed at which eiders were observed to start diving again (following time spent resting and digesting on the ice edge). which corresponds with the beginning of a steep decline in profitability predicted by our energetic model (Fig. 3). To evaluate the predicted upper limit to profitability, we considered the fastest current speeds in which eiders dove during the very strong current profiles associated with a new moon and approaching spring equinox. We emphasise that foraging time is particularly constrained during these extreme current regimes and that eiders normally do not dive in currents this fast. During these strong current regimes observed on 6 March and 7 March 2003, our model prediction of $1.21 \mathrm{~m} \mathrm{~s}^{-1}$ was just within $1 \mathrm{SD}$ of the current speed at which eiders returned to the water after resting and digesting on the ice edge during peak currents (Fig. 4), although on average individuals did not forage at current speeds over $\sim 1.0 \mathrm{~m} \mathrm{~s}^{-1}$. This suggests good support for the upper limits to profitability predicted by the energetic model. It is noteworthy that at a slightly higher current speed of $1.3 \mathrm{~m} \mathrm{~s}^{-1}$, it is likely that eiders are unable to maintain position during surface swimming (Hawkins et al. 2000), which could also pose an upper current speed limit to foraging.

These results indicate that fast current speeds can reduce profitability and restrict the time available for 


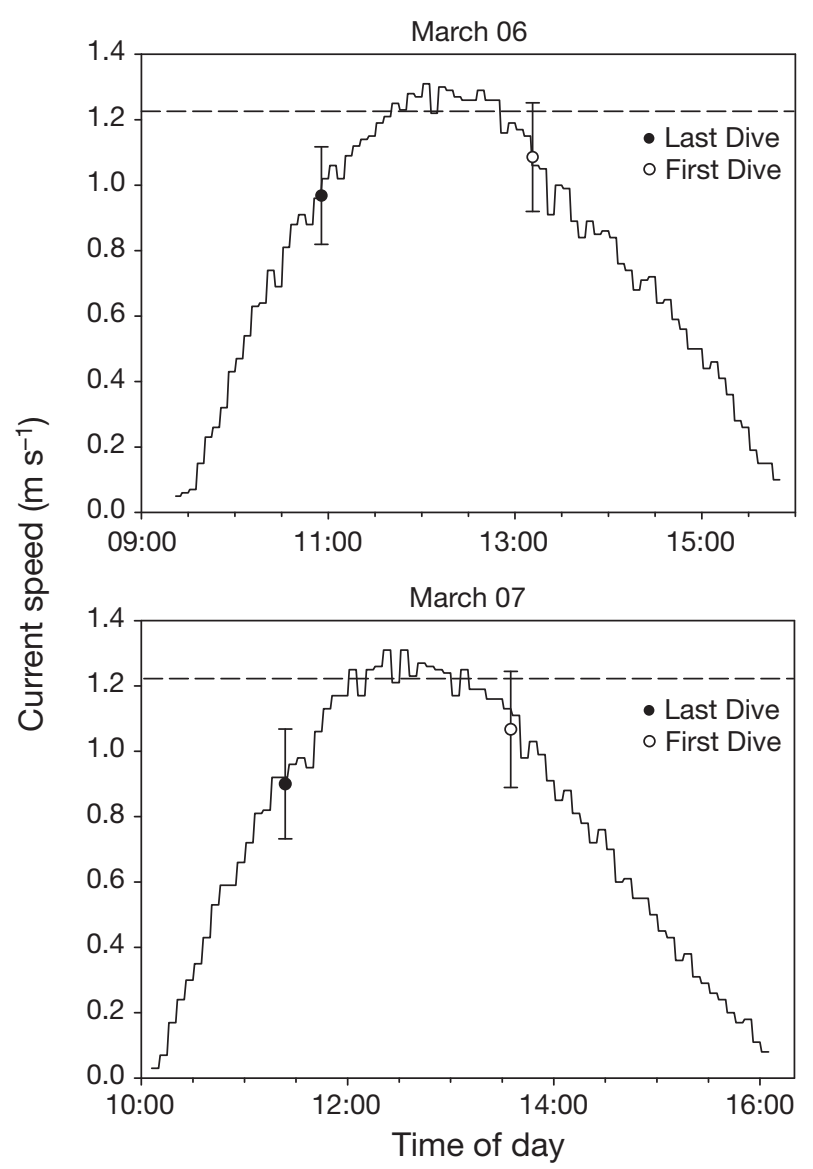

Fig. 4. Somateria mollissima sedentaria. The average current speed $\left(\mathrm{m} \mathrm{s}^{-1} \pm \mathrm{SD}\right)$ at which individual eiders made their (black circle) last and (white circle) first dives around peak tidal current regimes associated with a new moon on 6 March and 7 March 2003. Solid line: current profile; dashed horizontal line: predicted critical current speed (see Fig. 3). Individuals rested on the ice edge during peak currents and began to dive again at an average current speed of $\sim 1.0 \mathrm{~m} \mathrm{~s}^{-1}$. The predicted critical current speed fell just under $1 \mathrm{SD}$ above this observed value, indicating good support for the energetic model

foraging. This has important implications for balancing energy budgets, particularly for eiders diving in sea ice habitats in mid-winter. We discuss below the relative influence of the various energetic parameters on the results of the model, the possible role of physiological and morphological constraints on diving in currents, tradeoffs associated with resting on the ice, and potential implications of the non-linear relationship between current speed and diving energetics for longer term behavioural dynamics of foraging animals.

\section{The relative importance of intake rate}

We conducted sensitivity analyses across a broad range of parameter estimates in the model. Overall, the decelerating shape of the relationship between net energy gain and current speed was very robust, even to substantial changes in our energy expenditure and intake rates. Intake rate did have a strong influence on the intercepts: i.e. the predicted net intake at slack currents, as well as the critical current speed threshold at which diving was no longer profitable. Even across extensive sensitivity analyses, the predicted critical current speed was still within the range of tidal conditions observed at polynyas in the Belcher Islands, as well as being within the range of current speeds at which eiders stopped foraging (Fig. 4, Table 2). This suggests that intake rate during time at depth is likely to be the most important biological factor influencing the energy budgets of eiders, particularly in strong currents when time at depth for foraging is substantially reduced. Quantitative evaluation of field intake rates are substantially lacking in the literature for many diving species; the present analysis emphasises the importance of obtaining more accurate estimates and of considering the potentially wide variation in prey availability and energy content that occurs in the wild.

While prey intake rate may be relatively constant for some species or habitats (e.g. ad libitum food for diving birds at aquaculture sites), variability in intake rate could be particularly important in some situations. Given that mussels are sessile prey, we assumed a constant intake rate during time at depth. However, in practice over short time scales, intake rates will not be continuous and will involve the discrete capture of individual mussels (or small clumps). Therefore, some periods during foraging at depth are expected to be more successful than others; an average intake rate might only be achieved over several dives of variable success. While a continuous intake rate is a suitable assumption for the purposes of the present model, in faster currents when there is shorter time at depth during which to forage (Heath et al. 2007), consideration of the discrete capture of prey items could be more important as intake rate per dive potentially becomes more variable. If this is the case, then diving in faster currents could be a risk prone strategy (Stephens and Krebs 1986) and we predict that individuals in better condition should stop foraging and climb out onto the ice edge earlier (i.e. in slower currents) than individuals in poorer condition. Given the importance of intake rate at depth emphasised by the energetic model, increasing variability in energy intake while foraging in fast currents could be an important consideration for foraging eiders. While field intake rates are difficult to quantify, natural variability in prey abundance, quality or other factors influencing intake are likely to be substantially greater than these errors of estimation. Our results indicate that this variability in prey intake will 
be a major factor in determining the conditions under which diving is profitable.

While activities such as descent during diving are costly, they only occur for a brief proportion of the dive cycle. We found that resting and swimming on the surface, while cheaper than diving, still constituted a significant proportion of the energy costs per dive cycle. Travel time (descent and ascent) increases with tidal current speed, leading to a decrease in time available for foraging at depth within aerobic limits (Heath et al. 2007). Benthic prey is unlikely to be of sufficient energy content to make substantially more expensive anaerobic diving a profitable activity. The energetic model indicates that, under non-linearly decreasing bottom times as current speed increases, the cost of lost foraging time has a stronger negative influence on energy budgets than the various increasing costs of energy expenditure. Given the importance of intake rate, factors such as prey availability and the ability to locate and exploit profitable foraging patches at depth are therefore critical factors for eiders wintering in sea ice habitats. This could include various components of foraging such as searching ability, prey selection (e.g. size selection or other prey such as sea urchins or fish), capture efficiency and other factors which influence foraging success, such as memory of foraging patches, social information and interference competition (Stephens \& Krebs 1986). For eiders wintering in the arctic, sea ice extent increases through the winter forcing individuals closer together, which is likely to increase competition and prey depletion (Gilchrist et al. 2006). The importance of intake rate therefore has implications for future studies investigating how energy budgets can be influenced by potential increases in the variability of sea ice extent and dynamics associated with environmental change in Hudson Bay.

\section{Resting on the ice, risk of injury and predation risk}

When currents are strong, we observed that eiders stop foraging and rest out of water on the ice edge. Observational data indicates this often occurs close to current speeds at which the model predicts the beginning of a steep decline in profitability (i.e. $0.8 \mathrm{~m} \mathrm{~s}^{-1}$ : Fig. 3). The fastest currents eiders were observed diving in, during constraints of a very strong current regime, also corresponded with the upper limits of profitability predicted by our energetic model. Of course, eiders have to balance energy budgets over a longer time scale than a single dive cycle (e.g. on ice in fast currents and overnight); in the long term, foraging may not be worthwhile at even slower current velocities than predicted by energetics over a single dive cycle.
There are a number of additional factors that could influence the current speed at which eiders stop foraging and get out of the water. Our estimate of energy cost while the birds are resting on ice is $4.0 \mathrm{~W} \mathrm{~kg}^{-1}$ lower than when resting on water in slack currents: a substantial energy saving. This difference would be even greater as current speed increases swimming costs. Energy expenditure whilst at rest on the ice could be further reduced by huddling in a flock, but could also be increased by environmental factors such as declining air temperature and increasing wind speed (measured at $-70^{\circ} \mathrm{C}$ on several occasions). Additionally, resting on the ice makes individuals susceptible to predation by arctic foxes Vulpes lagopus and snowy owls Bubo scandiacus. Therefore, it may only be worth the long term reduction in energetic costs when the difference between the energetics of surface swimming and resting on ice are substantial (e.g. at high current velocities) and/or when resting is done in conjunction with conspecifics (for the benefits of huddling and predator dilution). It is likely that eiders consider a combination of these factors when deciding when to rest on the ice edge.

\section{Depth}

Studies on diving animals to date have focused primarily on how the energetics of diving changes with depth. Our approach can be easily adapted to consider depth by changing the energetic costs of buoyancy and drag as a function of depth (e.g. see Lovvorn et al. 2009). For example, our approach could be used as a starting point to predict the maximum depth that will allow profitable foraging for a given current speed. This could be particularly useful when quantifying the suitability of habitats that vary in depth characteristics and tidal current regimes. This research demonstrates that when current speeds are high (e.g. $>0.5 \mathrm{~m} \mathrm{~s}^{-1}$ ), as at our study site, it can strongly affect the behaviour and energetics of foraging by diving animals. The fact that eiders generally did not forage at current speeds greater than $0.8 \mathrm{~m} \mathrm{~s}^{-1}$ suggests that slower current speeds than our predicted upper limit can also have important effects on energy balance and should be evaluated and accounted for in analyses of diving.

\section{Maximum sustainable swimming speeds}

Research from flume tank studies indicates that common eiders cannot maintain surface swimming position at current speeds $>\sim 1.3 \mathrm{~m} \mathrm{~s}^{-1}$ (Hawkins et al. 2000). To avoid truncating model output, we assumed that, even at faster current speeds, eiders still swim at 
a maximum of $1.3 \mathrm{~m} \mathrm{~s}^{-1}$ (e.g. surface position is influenced by currents). In addition to the constraint of net energy balance over the dive cycle, a physical limitation to swim speed may also have an influence on when eiders get out of the water to rest on the sea ice. While eiders often stop foraging and rest on the ice at much slower current speeds than this potential limit, it could be an important consideration in fast current regimes (like those presented in Fig. 4).

Similarly, for underwater propulsion, it has been suggested that a narrow range of efficient muscle contraction rates could be an important factor explaining relatively constant stroke rates across several species of diving birds (Lovvorn et al. 2004, Watanuki et al. 2005, Heath et al. 2006). During descent, eiders at our field site maintained a relatively constant stroke rate $(2.28 \pm 0.23 \mathrm{~Hz})$ and swimming speed $(1.25 \pm$ $0.14 \mathrm{~m} \mathrm{~s}^{-1}$ ) across oncoming current speeds ranging from 0.0 to $1.0 \mathrm{~m} \mathrm{~s}^{-1}$ (Heath et al. 2006). It is interesting that our energetic dive cycle model independently predicted a non-profitable current speed threshold of $1.21 \mathrm{~m} \mathrm{~s}^{-1}$, just under the consistent swimming speed of eiders during descent. Faster currents would necessitate swimming outside of this range of normal swimming speeds. Energetic costs might be expected to accelerate as conditions approach the physiological and morphological limits of the organism, which is an interesting topic as all these constraints have likely coevolved.

\section{Summary and implications}

Our results indicate that costs of surface swimming and diving can exceed the gains from foraging given adequate increases in current speed. Despite increased predation risk, eiders got out of the water and onto the ice edge at current velocities corresponding with a steep decrease in profitability and did not dive in currents faster than the upper limits predicted by the model. Therefore, while tidal currents can maintain predictable open water habitats for wintering eiders (e.g. polynyas), strong currents reduce profitability and can enforce resting periods: they therefore limit the time available to forage per day in these habitats. This has consequences for daily energy budgets in mid-winter, and indicates the importance of considering current speed in field studies of diving animals.

Acknowledgements. This project was a joint collaboration between the Canadian Wildlife Service (CWS), the Community of Sanikiluaq, Nunavut, the Nunavut Wildlife Management Board, and Simon Fraser University. We greatly appreciate support received from the Sanikiluaq Hunters and Trappers Association (particularly L. Arragutainaq), D. Searle of the Mitiq Cooperative, the local school and members of the community of Sanikiluaq. Field work would not have been possible without the in-depth knowledge and experience of our Inuit collaborators, particularly: S. Kavik, E. Oqaituk, L. Ippaq and J. Oqaituk. K. Allard, P. Smith, R. Bryant, K. Woo, M. Mallory and S. Gilliand also assisted with field work. G. Robertson was instrumental in establishing logistics and community relations with H.G.G. Research funding was provided by the CWS, the Nunavut Research Trust, the Polar Continental Shelf Project, the Sea Duck Joint Venture, the Canadian Northern Studies Trust, World Wildlife Fund Canada and the Northern Scientific Training Program. Scholarship funding to J.P.H. was provided by a Natural Sciences and Engineering Research Council Postgraduate Scholarship$B$ and the Centre for Wildlife Ecology at Simon Fraser University. Thanks to R. C. Ydenberg, D. Esler, T. D. Williams, D. Kramer, J. Lovvorn and anonymous reviewers for their valuable comments and feedback on the manuscript.

\section{LITERATURE CITED}

Bevan RM, Keijer E, Butler PJ (1992) A method for controlling the feeding behaviour of aquatic birds: heart rate and oxygen consumption during dives of different duration. J Exp Biol 162:91-106

Brinkman AG, Ens BJ, Kats R (2003) Modeling the energy budget and prey choice of eider ducks. Alterra-rapport 839, Alterra, Wageningen

Brodsky LM, Weatherhead PJ (1984) Behavioural thermoregulation in wintering black ducks: roosting and resting. Can J Zool 62:1223-1226

Bustnes JO (1998) Selection of blue mussels, Mytilus edulis, by common eiders, Somateria mollissima, by size in relation to shell content. Can J Zool 76:1787-1790

Bustnes JO, Erikstad KE (1990) Size selection of common mussels, Mytilus edulis, by common eiders, Somateria mollissima: energy maximization or shell weight minimization? Can J Zool 68:2280-2283

> Chappell MA, Morgan KR, Souza SL, Bucher TL (1989) Convection and thermoregulation in two Antarctic seabirds. J Comp Physiol B 159:313-322

Croll DA, McLaren E (1993) Diving metabolism and thermoregulation in common and thick-billed murres. J Comp Physiol B 163:160-166

De Leeuw JJ (1996) Diving costs as a component of daily energy budgets in aquatic birds and mammals: generalizing the inclusion of dive-recovery costs demonstrated in tufted ducks. Can J Zool 74:2131-2142

Frederick RB, Klaas EE (1982) Resource use and behavior of migrating snow geese. J Wildl Manag 46:601-614

Gabrielsen GW, Mehlum F, Karlsen HE, Andresen O, Parker $\mathrm{H}$ (1991) Energy cost during incubation and thermoregulation in the female common eider Somateria mollissima. Nor Polarinst Skr 195:51-62

Gilchrist HG, Robertson GJ (2000) Observations of marine birds and mammals wintering at polynyas and ice edges in the Belcher Islands, Nunavut, Canada. Arctic 53:61-68

Gilchrist HG, Heath JP, Arragutainaq L, Robertson GJ, Allard K, Gilliland S, Mallory M (2006) Combining scientific and local knowledge to study common eider ducks wintering in Hudson Bay. In: Oakes J, Riewe R (eds) Climate change: linking traditional knowledge and scientific knowledge. University of Manitoba Aboriginal Issues Press, Winnipeg

> Grémillet D, Tuschy I, Kierspel M (1998) Body temperature and insulation in diving great cormorants and European shags. Funct Ecol 12:386-394

Guillemette M (1994) Digestive-rate constraint in wintering 
common eiders (Somateria mollissima): implications for flying capabilities. Auk 111:900-909

Guillemette M, Ydenberg RC, Himmelman JH (1992) The role of energy intake in prey and habitat selection of common eiders Somateria mollissima in winter: a risksensitive interpretation. J Anim Ecol 61:599-610

Hamilton DJ (2000) Direct and indirect effects of predation by common eiders and abiotic disturbance in an intertidal community. Ecol Monogr 70:21-43

Hamilton DJ, Nudds TD, Neate J (1999) Size-selective predation of blue mussels (Mytilus edulis) by common eiders (Somateria mollissima) under controlled field conditions. Auk 116:403-416

Hawkins PAJ, Butler PJ, Woakes AJ, Speakman JR (2000) Estimation of the rate of oxygen consumption of the common eider duck (Somateria mollissima), with some measurements of heart rate during voluntary dives. J Exp Biol 203:2819-2832

Heath JP (2007) Diving and foraging by common eiders wintering in the Canadian Arctic: managing energy at multiple time scales. PhD dissertation, Simon Fraser University, Burnaby, BC

Heath JP, Gilchrist HG, Ydenberg RC (2006) Regulation of stroke patterns and swim speed across a range of current velocities: diving by common eiders wintering in polynyas in the Canadian arctic. J Exp Biol 209:3974-3983

- Heath JP, Gilchrist HG, Ydenberg RC (2007) Can dive cycle models predict patterns of foraging behaviour? Diving by common eiders in an Arctic polynya. Anim Behav 73: $877-884$

Houston AI, Carbone C (1992) The optimal allocation of time during the dive cycle. Behav Ecol 3:255-265

Jenssen BM, Ekker M, Bech C (1989) Thermoregulation in winter-acclimatized common eiders (Somateria mollissima) in air and water. Can J Zool 67:669-673

Kaseloo PA, Lovvorn JR (2006) Substitution of heat from exercise and digestion by ducks diving for mussels at varying depths and temperatures. J Comp Physiol B 176:265-275

Lovvorn JR, Jones DR, Blake RW (1991) Mechanics of underwater locomotion in diving ducks: drag, buoyancy and acceleration in a size gradient of species. J Exp Biol 159: 89-108

Lovvorn JR, Watanuki Y, Kato A, Naito Y, Liggins GA (2004) Stoke patterns and regulation of swim speed and energy

Editorial responsibility: Rory Wilson,

Swansea, UK costs in free-ranging Brünnich's guillemots. J Exp Biol 207:4679-4695

Lovvorn JR, Grebmeier JM, Cooper LW, Bump JK, Richman SE (2009) Modeling marine protected areas for threatened eiders in a climatically changing Bering Sea. Ecol Appl 19:1596-1613

Nehls G (1995) Strategien der Ernährung und ihre Bedeutung für Energiehaushalt und Ökologie der Eiderente (Somateria mollissima) (L., 1958). PhD dissertation, University of Kiel, Kiel

Paulus SL (1984) Behavioral ecology of mottled ducks in Louisiana. PhD dissertation, Auburn University, Auburn, $\mathrm{AL}$

Piersma T, Koolhaas A, Dekinga A (1993) Interactions between stomach structure and diet choice in shorebirds. Auk 110:552-564

Richman SE, Lovvorn JR (2003) Effects of clam species dominance on nutrient and energy acquisition by spectacled eiders in the Bering Sea. Mar Ecol Prog Ser 261: 283-297

Richman SE, Lovvorn JR (2008) Costs of diving by wing and foot propulsion in a sea duck, the white-winged scoter. J Comp Physiol B 178:321-332

Schoener TW (1971) Theory of feeding strategies. Annu Rev Ecol Syst 2:369-404

Stephens DW, Krebs JR (1986) Foraging theory. Princeton University Press, Princeton, NJ

Stephenson R (1994) Diving energetics in lesser scaup (Aythya affinis, Eyton). J Exp Biol 190:155-178

Stephenson R, Lovvorn JR, Heieis MRA, Jones DR, Blake RW (1989) A hydromechanical estimate of the power requirements of diving and surface swimming in lesser scaup (Aythya affinis). J Exp Biol 147:507-519

- Watanuki Y, Takahashi A, Daunt F, Wanless S, Harris M, Sato K, Naito Y (2005) Regulation of stroke and glide in a footpropelled avian diver. J Exp Biol 208:2207-2216

- Wilson RP, Hustler K, Ryan PG, Burger AE, Noldeke EC (1992) Diving birds in cold water: Do Archimedes and Boyle determine energetic costs? Am Nat 140:179-200

Woakes AJ, Butler PJ (1983) Swimming and diving in tufted ducks, Aythya fuligula, with particular reference to heart rate and gas exchange. J Exp Biol 107:311-329

Ydenberg RC, Guillemette M (1991) Diving and foraging in the common eider. Ornis Scand 22:349-352

Submitted: September 17, 2009; Accepted: January 6, 2010 Proofs received from author(s): March 4, 2010 